\title{
ПРОБЛЕМЫ КОНТРОЛЯ ФИЛЬТРАЦИИ ВОД ЧЕРЕЗ ГИДРОТЕХНИЧЕСКИЕ СООРУЖЕНИЯ В УСЛОВИЯХ ВЕЧНОЙ МЕРЗЛОТЫ
}

\author{
Юркевич Николай Викторович 1 , \\ YurkevichNV2@ipgg.sbras.ru
}
Юркевич Наталия Викторовна' YurkevichNV@ipgg.sbras.ru

Гуреев Вадим Николаевич1,2, GureyevVN@ipgg.sbras.ru

\section{Мазов Николай Алексеевич1, MazovNA@ipgg.sbras.ru}

1 Институт нефтегазовой геологии и геофизики им. А.А. Трофимука СО РАН, Россия, 630090, г. Новосибирск, пр. Академика Коптюга, 3.

2 Новосибирский государственный технический университет, Россия, 630087, ул. Немировича-Данченко, 136.

\begin{abstract}
Актуальность работы обусловлена экологическими рисками в связи с техногенным растеплением многолетнемерзлых грунтов в местах складирования отходов горно-добывающих предприятий в условиях Крайнего Севера.

Цель: анализ мирового опыта по проблемам деградации мерзлоты, развития фрильтрационных каналов в трещиноватых тектонических зонах, влекущих утечки оборотных вод из хвостохранилищ горно-обогатительных предприятий, и поиску технологических решений, направленных на снижение фильтрационного потока и предотвращение экологических проблем.

Методы: ретроспективный анализ публикаций, отобранных в результате поиска в отечественных и международных библиографических базах данных, включая реферативный журнал ВИНИТИ РАН, Российский индекс научного цитирования и библиографический указатель Scopus компании Elsevier, с 2000 г. по настоящее время.

Результаты. Контроль и предотвращение фильтрации вод через плотины хвостохранилищ, горно-обогатительных предприятий и прилегающий горный массив в условиях вечной мерзлоты осуществляется преимущественно при помощи мероприятий по управлению температурным режимом грунтов, сооружению противофильтрационных экранов и завес, использования тампонажных технологий. Основные освещенные в литературе методы тампонажа включают использование растворов на основе портландиемента, облегчающих добавок (алюмосиликатные микросферы), расширяющего компонента и жидкости затворения (раствор хлористого кальция); тампонажных смесей на основе гипса, бруситового каустического порошка, сернокислого магния, торфа. Перспективным направлением в разработке противофильтрационных мероприятий на предприятиях, расположенных в районах Севера и вечной мерзлоты, является использование криогелей, создающих завесу, которая упрочняется при замораживании и оттаивании. Анализ публикаций за период с 2000 г. по настоящее время показал, что несмотря на актуальность проблемы утечек фильтрационных вод на хвостохранилищах горнодобывающих предприятий, отмечается ограниченность опубликованных разработок и недостаток технической литературы по этому направлению.
\end{abstract}

\section{Ключевые слова:}

Вечная мерзлота, растепление грунтов, гидротехнические сооружения, плотина, дамба, хвостохранилище, обзор.

\section{Введение}

Эксплуатация хвостохранилищ горно-обогатительных предприятий имеет ряд экологических последствий, в том числе в связи с окислением тонкоизмельченных хвостов обогащения руды кислородом воздуха и воды с формированием минерализованных дренажных вод, миграция которых за пределы хранилищ приводит к загрязнению поверхностных и подземных вод региона [1-4]. Кроме того, процессы взаимодействия «вода-хвосты» в условиях Крайнего Севера зачастую приводят к растеплению многолетнемерзлых грунтов, формированию техногенных таликов, утечкам техногенных вод, что в случае наличия разломных зон приводит к развитию фильтрационных каналов.

Целью работы является анализ мирового опыта по техническим особенностям возведения плотин хвостохранилищ в зоне вечной мерзлоты, техническим решениям по контролю и предотвращению фильтра- ции вод через плотины, проблемам прогнозирования растепления грунтов, надежности защиты плотин от возможных аварий.

Исследование актуально как для инженеров и технологов горнорудной промышленности, так и для специалистов в областях наук о Земле, горного дела и экологии. Высокий интерес к данной проблематике проявляют научные организации и коммерческие компании Российской Федерации, Соединенных Штатов Америки, Канады, а также Китая и стран Средней Азии, высокогорные районы которых имеют схожие с российскими условия низких температур и вечной мерзлоты.

\section{Материалы и методы}

При выполнении настоящей работы использовались источники, отобранные в результате поиска в отечественных и международных библиографических 
базах данных, включая реферативный журнал ВИНИТИ РАН, Российский индекс научного цитирования и библиографический указатель Scopus компании Elsevier, преимущества которого перед иными базами данных хорошо освещены в работе [5]. Ретроспективный анализ включает публикации за 20-летний период - с 2000 г. по настоящее время. В реферативном журнале ВИНИТИ в качестве тематических ограничителей были выбраны направления «Геология», «Геофизика», «Горное дело» и «Охрана окружающей среды»; в базе данных Scopus - рубрика по наукам о Земле - Earth and Planetary Sciences. В качестве запроса использовались следующие термины в различных комбинациях: вечная мерзлота, растепление, деградация мерзлоты, опасные экзогенные геологические процессы, фильтрация через трещиноватые тектонические зоны, оборотные техногенные воды, хвостохранилище, пульпа, дамба, утечки, каналы фильтрации, ликвидация каналов, тампонажные технологии, геотермальный насос, мерзлотоведение, замораживание грунтов, криогель, цементирование трещин, подземные воды. При поиске зарубежных источников использовались соответствующие англоязычные термины.

В итоге для экспертного анализа было отобрано более 60 наиболее пертинентных источников, значительная часть которых российские. Это связано с климатическими условиями вечной мерзлоты и их наибольшей площадью в сравнении с другими странами, что и обусловило особенную актуальность тематики именно для Российской Федерации.

\section{1. Технические особенности возведения плотин хвостохранилищ в зоне вечной мерзлоты}

Значительная часть исследований посвящена проблемам возведения плотин в зоне вечной мерзлоты. Особое значение для гидротехнических сооружений (далее - ГТС) в криолитозоне имеет выбор принципа строительства. Для сохранения вечномерзлых грунтов в естественном состоянии часто проектируются сложные в исполнении и пользовании охлаждающие и замораживающие технологические системы. Например, в работах $[6,7]$ на примере хвостохранилища «Лебяжье», расположенного на севере Красноярского края, описан способ зенитного намыва ограждающей дамбы, позволивший выявить преимущества и недостатки этого подхода перед традиционным способом создания плотин. Отмечено, что общим недостатком традиционного и зенитного способов складирования хвостов является отсутствие приборов контроля, способных распознавать аварийные ситуации. Чтобы предупредить ситуацию, при которой опорожнение распределительного пульпопровода в случае его внезапной или плановой остановки невозможно, намыв рекомендуется осуществлять короткими пляжами с крутым заложением, что позволяет производить разгрузку пульпопровода через сосредоточенные выпуски. В качестве основных преимуществ зенитного намыва можно выделить: а) снижение материальных и финансовых затрат, б) формирование дамбы устойчивой конструкции, в) сохранение емкости, г) высокое качество пляжа. Проведенный эксперимент показал высокую экологическую эффективность производства работ, поскольку поступления техногенных вод за пределы хвостохранилища практически не наблюдалось, в связи с чем техногенная нагрузка хвостохранилища на окружающую природную среду снизилась.

Другой пример возведения дамбы хвостохранилища в Красноярском крае [8] включает технологию отсыпки в пляжной зоне кольевой пульпоулавливающей призмы, позволившей за летний период намыва произвести подъем гребня ограждающей дамбы, создать емкость, достаточную для оборотного водоснабжения и зимнего подледного складирования хвостов, обеспечить естественное промерзание тела дамбы и соответственно фильтрационную и статическую устойчивость ограждающих конструкций, а также повысить экологическую безопасность сооружения. Для ликвидации аварийных утечек техногенных вод из мерзлотной противофильтрационной завесы и обеспечения устойчивости плотины хвостохранилища Надеждинского металлургического завода, расположенного в Свердловской области, была реализована технология создания противофильтрационного экрана из отвальных хвостов на верховом откосе плотины с одновременным введением в действие насосной станции по перехвату фильтрационных потерь из хвостохранилища в нижнем бьефе и введением в действие дренажных скважин. Проведенные мероприятия сопровождались понижением температур грунтов основания, уменьшением границ талых пород и повышением устойчивости сооружения.

Существенное внимание уделяется выбору и обоснованию времени строительства дамб, так как период промерзания, а также температурное поле будут различаться, учитывая время строительства дамбы, теплофизические характеристики и влажность грунтов и размеры плотины. Установлено, что высота дамбы при ее возведении летом не должна превышать 6 м ввиду отсутствия в теплое время года необходимого температурного режима, значимого для фильтрационной и статической устойчивости. В то же время при возведении ГТС зимой в ее основании и теле уже в первый год создается отрицательный температурный режим (не выше $-2{ }^{\circ} \mathrm{C}$ в ядре) [9]. Следовательно, рекомендуется уже в первый год формировать ядро плотины в зимнее время, используя метод послойного намораживания грунтов, с тем чтобы создать в теле дамбы устойчивый противофильтрационный экран из мерзлого грунта.

Для строительства гидротехнических сооружений с повышенными противофильтрационными и прочностными характеристиками также рекомендуется одновременное использование строительства плотин «мерзлого» типа и подхода, основанного на воднотепловой мелиорации [10]. В условиях вечной мерзлоты это обеспечивает ряд преимуществ, включая снижение объемов выполняемых работ при эксплуатации месторождений, отказ от применения буровзрывного рыхления песков, уменьшение землеемкости, снижение трудозатрат на выполнение транспортных 
работ и также снижение выбросов вредных веществ. На примере Нюрбинского горно-обогатительного комбината, который находится в Якутии, для регионов распространения многолетнемерзлых грунтов показана эффективность проектирования, строительства и безопасной эксплуатации насыпных низконапорных плотин [11]. Возможности обеспечения устойчивости сооружения путем управления мерзлотно-грунтовыми условиями с помощью специальных технологий строительства и эксплуатации показаны на примере двух разнотипных хвостохранилищ Норильского промышленного района, находящегося на севере Красноярского края [12].

В исследованиях $[13,14]$ обсуждаются возможные конструктивные и технологические подходы при строительстве накопителей промышленных отходов. Незамерзающая дренажная система таких накопителей позволяет использовать их даже при значительном промерзании внешнего откоса. Конструкция подобного накопителя позволяет регулировать глубину оттаивания, а каскадная схема расположения позволяет исключить фильтрацию из накопителя.

Особое внимание при возведении плотин хвостохранилищ на вечномерзлых грунтах уделяется проблеме улавливания стоков. Например, система улавливания стоков может включать фильтрующую дамбу и трубчатый дренаж, дренажно-пригрузочную призму, расположенную в нижней части дамбы со стороны ее низовой грани, водонепроницаемый экран, размещенный на дренажно-пригрузочной призме, зуб из водопроницаемого материала, расположенный под дренажно-пригрузочной призмой и соединенный верхней частью с водонепроницаемым экраном, а нижней частью - с зоной вечной мерзлоты, пруднакопитель, расположенный на расстоянии от зуба не менее удвоенной мощности вечномерзлых пород и выполненный с дном из слоев водонепроницаемого материала с расположенными между ними слоями теплоизоляции [15].

В условиях растепления многолетнемерзлых грунтов береговых примыканий ограждающих дамб, влекущего развитие фильтрационных каналов и утечку оборотных вод, встает вопрос о предотвращении фильтрации вод, которое находит решение в нескольких аспектах. Сюда относятся меры по прогнозированию растепления грунтов, надежности защиты плотин и возможных аварий, мероприятия по поддержанию мерзлоты и по защите от растепления, созданию противофильтрационных (тампонажных, мерзлотных) экранов и завес и применению различного рода инъекций для борьбы с утечками через разломные зоны в местах складирования горнорудной промышленности.

\section{2. Технические решения по контролю} и предотвращению фильтрации вод через плотины

2.1. Управление температурным режимом грунтов для поддержания мерзлоты и для защиты от растепления

Ряд исследований посвящен выбору теплоизолирующих материалов, предотвращающих растепление горных пород. Авторами исследования [16] разработана математическая модель, учитывающая теплооб- менные процессы в карьере, которая дает возможность сделать прогноз по формированию температурного поля в массиве горных пород уступа карьера с учетом конструкции уступа, теплофизических свойств пород, климатических условий, а также геометрических размеров теплоизоляции поверхностей уступа. Полученные в ходе работы результаты демонстрируют перспективность применения разработанного подхода к управлению устойчивостью борта карьера, который дает возможность в летний сезон снизить фильтрацию и предотвратить растепление бортов карьера атмосферным теплом.

Активное управление температурным режимом грунтов в ограждающих дамбах хвостохранилищ на Севере может быть достигнуто с помощью использования сезоннодействующих охлаждающих устройств различного типа: воздушных с вынужденной конвекцией воздуха, жидкостных с естественной конвекцией хладоносителя-керосина, жидкостных с вынужденной конвекцией хладоносителя и парожидкостных, или двухфазных [17]. При этом противофильтрационные и несущие нагрузку элементы ГТС создаются замораживанием влаги, содержащейся в грунте, до его твердомерзлого состояния. Сохранению пород от растепления может способствовать широко используемая за рубежом надпакерная жидкость на углеводородной основе [18].

Предотвратить растепление мерзлых пород позволяют также системы теплоизолирующих труб. На примере Уренгойской группы месторождений Ямало-Ненецкого автономного округа показаны возможности применения теплоизолированных конструкций, представляющих собой стальные трубы диаметром от 57 до 1220 мм с теплоизоляцией из пенополиуретана в гидрозащитной оболочке по типу «труба в трубе» в полиэтиленовой оболочке [19]. Опыт температурной стабилизации грунтов с использованием системы «ВЕТ» на примере ЮжноХыльчуюского (ЯНАО) и Ванкорского (Красноярский край) месторождений представлен в работах [20, 21]. Проведены исследования по совершенствованию и повышению надежности системы «ВЕТ». В частности, исключено пересечение труб, в результате чего снижено взаимодействие хладагента с конденсатором и испарителем и взаимный контакт поверхностей труб во избежание разрушения защитного покрытия.

\section{2. Противофильтрационные экраны и завесы, исключающие фильтрацию вод из накопителей}

Защита уступов бортов карьеров криолитозоны от растепления может осуществляться при возведении трех искусственных элементов: противофильтрационного экрана, защитной бермы и защитного покрытия [22]. Также для исключения фильтрации из хвостохранилища и обеспечения его полной экологической безопасности может использоваться устройство мерзлотной противофильтрационной завесы в нижней дамбе [14]. При создании противофильтрационных экранов на мерзлых грунтах в районах Крайнего Севера, Севера и районах сезонного уровня промерза- 
ния грунта ниже глубины укладки противофильтрационного экрана обосновывается применение бентонитовых матов [23].

Методами физического моделирования подробно исследованы различные варианты устройства противофильтрационных экранов и технологические особенности их намыва, включающие подготовку основания, снятие почвенно-растительного слоя, прокладку траншеи по периметру хвостохранилища, закладку контрольно-измерительной сети и опорной топогеодезической сети, заполнение хвостами траншеи в основании дамбы, намыв противофильтрационного экрана ложа хвостохранилища [24]. Фильтрационная устойчивость хвостохранилища может быть обеспечена с применением противофильтрационных завес и экранов, являющихся основными типами противофильтрационных конструкций. Результаты опробованы на хвостохранилище «Лебяжье» в Красноярском крае. Схожая технология применялась при строительстве хвостохранилища Норильского комбината, расположенного там же [6, 7].

Поскольку традиционные конструктивные решения и методы строительства не всегда пригодны в условиях распространения многолетнемерзлых грунтов и многие противофильтрационные экраны в условиях низких температур до $-50-60{ }^{\circ} \mathrm{C}$ не сохраняют свою герметичность, для создания мерзлотных завес применяются различные специальные технологии, например системы «ГЕТ», сезоннодействующие парожидкостные энергонезависимые системы «ВЕТ» или индивидуальные термостабилизаторы. Технологии выполнения таких работ использовались на Юбилейном и Бованенковском месторождениях ЯмалоНенецкого автономного округа $[25,26]$.

Защита от фильтрации в условиях криолитозоны может быть также осуществлена с помощью прокладки у дна потенциально опасного участка водотока трубы, которая обеспечивала бы пропуск по меньшей мере воды водотока в объеме начала холодного периода [27].

2.3. Тампонажные технологии предотвращения фильтрации вод через плотины в условиях вечной мерзлоты

С учетом исключительно высокой стоимости активной и пассивной защиты многолетнемерзлых пород от растепления существенное внимание уделяется тампонажным технологиям. Значительный объем работ проводится по определению оптимальных тампонажных композиций для эффективной защиты дамб от фильтрации, поскольку пониженные температуры значительно увеличивают время ожидания затвердевания смесей, необходимое для набора растворами требуемой прочности, при которой возможно дальнейшее осуществление работ. Проблемы теплоизоляционных тампонажных материалов для условий многолетних мерзлых пород широко освещены в работе [28]. В исследовании [29] описан состав тампонажного раствора с повышенной гидравлической активностью при низких положительных и отрицательных температурах, твердение которых не сопровождается усадочными деформациями. Раствор включает тампонажный портландцемент, облегчающую добавку - алюмосиликатные микросферы (10-15 \%), расширяющий компонент - ОТОС (10\%) и жидкость затворения - 4\%-й раствор хлористого кальция. Полученные данные свидетельствуют, что такой тампонажный раствор характеризуется удовлетворительными прочностью, сроками схватывания и значительным расширением, что позволяет рекомендовать его для цементирования в арктических условиях.

Проблемы разработки облегченных и сверхлегких растворов для использования в условиях аномально низких пластовых давлений и многолетних мерзлых пород рассмотрены в цикле работ Д.В. Орешкина с соавторами [28, 30-33]. В частности, разработан универсальный тампонажный материал, имеющий в своем составе полые стеклянные микросферы. Наибольшей эффективностью обладают тампонажные материалы с аппретированными микросферами и суперпластификаторами. При формировании тампонажного камня со стеклянными микросферами его структура и свойства значительно улучшаются; снижается общая пористость, а прочность растет более чем в два раза. Другая разработка этих же авторов для получения облегченного тампонажного раствора включает сырьевую смесь на основе тампонажного портландцемента, модифицирующей добавки, облегчающего наполнителя и жидкости затворения, где в качестве модифицирующей добавки содержится комплексная добавка длительной жизнеспособности «Murapor Combi 756», а в качестве наполнителя - полые керамические микросферы при соотношении ингредиентов (\%): тампонажный портландцемент - 38-53,5; полые керамические микросферы - 10,7-22,8; комплексная добавка «Murapor Combi 756» - 0,114-0,16; жидкость затворения - вода или 2-8\%-й раствор хлорида натрия или хлорида кальция - остальное. Такая сырьевая смесь позволяет повысить эффективность герметизации и защищает многолетние мерзлые породы от растепления [34].

Для тампонажа скважин в условиях многолетней мерзлоты эффективно применение смеси на основе типовых вяжущих и цемента. В работе [35] дана характеристика тампонажной смеси на основе гипса, которая отвечает специфическим требованиям тампонирования грунтов в условиях Крайнего Севера. В то же время разрабатываются безгипсовые технологии тампонажа. На примере Ямбургского месторождения Ямало-Ненецкого автономного округа представлены результаты исследования по безгипсовым сухим тампонажным смесям [36]. Практичные многокомпонентные смеси с использованием особых функциональных добавок не нуждаются в дополнительном трансфере и смешивании отдельных компонентов и сохраняют технологические характеристики при длительном хранении в открытых площадках.

Для оценки условий надежного тампонирования скважин газожидкостными тампонажными смесями в мерзлых породах проводился расчетный анализ температурного поля горного массива мерзлых пород с разной температурой, который позволил установить 
условия эффективного применения данных смесей [37]. Разработке тампонажного материала для использования в условиях многолетнемерзлых пород, характеризующихся сплошной и прерывистой льдистостью, посвящено исследование [38]. В составе тампонажной смеси предлагается использовать (в \%): порошок бруситовый каустический - 43,86-47,36; сернокислый магний - 8,32-13,81; воду, в результате чего был получен раствор с пониженной плотностью, который быстро схватывается и не растепляет льдистую породу.

Вопросы получения облегченных быстротвердеющих расширяющихся тампонажных составов для крепления многолетнемерзлых и трещиноватых пород, предотвращения гидроразрывов пласта, газопроявлений и растепления многолетнемерзлых пород находят освещение в работе [39], где в составе смеси предлагается использовать (в \%) тампонажный портландцемент для холодных скважин - 35,5-56,5; сернокислый алюминий $-2,0-5,0$ торф $-2,0-10,3$ и воду, что позволяет получить раствор с высокой степенью расширения, технологичными сроками схватывания при низких температурах, пониженной теплопроводностью и эффективной адгезией к металлу.

\section{4. Математическое моделирование}

для прогнозирования растепления грунтов

Важное значение придается вопросам надежности защиты многолетнемерзлых пород от растепления. В частности, уровень защиты от растепления может быть спрогнозирован путем изучения изменения влажности (влагопереноса) тампонажного камня [40]. Ряд прогностических исследований выполнен на примере Кумторского рудника, расположенного в Киргизии. В частности, для решения обратной задачи спецификации параметров места разрыва экрана использовалась нелинейная термогидромеханическая модель породы плотины хвостохранилища [41]. Кроме того, численные эксперименты позволили проанализировать, как размеры противофильтрационного экрана и смена температуры флюидов воздействуют на объем фильтрации в плотине. Авторы продемонстрировали, что на разрушение противофильтрационного экрана может указывать рост скорости изменения давления [42].

Прогнозная модель термического режима хвостохранилища на примере криолитозоны Магаданской области приводится в работе [43]. В частности, описаны результаты математического моделирования динамики температурного поля в отложениях хвостохранилища и окружающем массиве горных пород, определены параметры изолирующих грунтовых слоев, обеспечивающих мерзлое состояние складированных отходов, показана роль таких факторов, как конвекция воздуха в теле дамбы, режим заполнения хвостохранилища отходами и сезонно меняющиеся тепловые поля в окружающем породном массиве.

Составлена прогнозная модель сценария развития аварии на хвостохранилище, предусматривающая фильтрационные деформации в породе основания и тела плотины и размыв тела плотины, что приводит к ее разрушению [44]. Прогностическому расчету рас- тепления мерзлого грунта посвящено исследование [45], в котором предложена методика, учитывающая фазовые превращения лед-вода в массиве предварительно охлажденного (замороженного) грунта после отключения охлаждающей системы.

\section{3. Международный опыт решения проблем контроля и предотвращения фильтрации вод через дамбы}

Несмотря на актуальность проблемы фильтрационных вод на ГТС, связанных как с растеплением, так и с циклами «оттаивание-замерзание», а также проблемы подбора оптимальных растворов для создания различного рода завес, экранов, мембран, инъекций и пр., исследователи указывают на ограниченность разработок по этому направлению, равно как и на недостаток технической литературы по теме [46-49]. Обзор зарубежного опыта решения анализируемой проблемы показывает, что основная часть как научных исследований, так и технических разработок приходится на Канаду, которая имеет во многом схожие с российскими климатические условия и, как следствие, вынуждена решать схожие вопросы при постройке и дальнейшей эксплуатации гидротехнических сооружений в зонах вечной мерзлоты. Кроме того, зарубежные компании указывают на ограниченный и снижающийся объем финансирования для восстановления ГТС и соответствующую необходимость в разработке инновационных подходов к их поддержанию в состоянии, обеспечивающем безопасность окружающей среды $[46,50]$.

Следует отметить, что при решении вопросов снижения фильтрации в дамбах в условиях вечной мерзлоты зарубежными исследователями в основном применяются подходы, схожие с используемыми в отечественной практике. При этом анализ литературных данных показывает высокую долю вклада российских специалистов в решение проблемы. Детальный обзор по хвостохранилищам горнорудных предприятий, их физическим и химическим свойствам, повреждениям ограждающих дамб, воздействию технологических жидкостей на окружающую среду и обеспечение безопасности ГТС на хвостохранилищах проведен группой британских специалистов [50].

Значительный объем работ проводится канадскими инженерами и исследователями, работающими как в университетах, так и в технологических корпорациях. Так, на примере канадской ГTC Horizon Dam в качестве противофильтрационных мер в условиях холодного климата предлагается использовать метод «стена в грунте» [51]. В другом исследовании канадских специалистов из провинции Онтарио [52] рассматривается эффективность геомембран, способных обеспечить существенный барьер для утечки из хвостохранилищ: в опытной серии исследований была оценена чувствительность уровня просачивания к различным типам геомембран (линейный полиэтилен низкой плотности - LLDPE и полиэтилен высокой плотности - HDPE), размеру отверстия, эффекту морщин, эффекту регулярности контактов, давлению, проницаемости хвостов и проницаемости подкладки. Результаты испытаний показали, что утечка из хво- 
стовых систем или систем геомембранного вкладыша на несколько порядков меньше, чем утечка из типовых систем. Исследование подтвердило, что практика, предполагающая укладку «дренажного» слоя поверх геомембранного вкладыша с целью уменьшения напора на него, непродуктивна, поскольку обеспечивает путь для утечки из вышележащих уплотняющих слоев. Это наблюдение в сочетании с тем, что большинство отверстий в геомембранных вкладышах образуются во время размещения вышележащего дренажного или защитного слоя, подтверждает, что оптимальным практическим подходом является обеспечение того, чтобы хвосты были размещены непосредственно над геомембранным вкладышем. В рамках исследования также показано, что старение геомембран значительно снижается при постоянной температуре, а оптимизация материалов и окислителей, которые используются для изготовления вкладыша, может увеличить срок его службы.

Проблеме создания противофильтрационного экрана в условиях вечной мерзлоты северной части Канады посвящена работа [53], где создание экрана проводилось в рамках расширения хвостохранилища. Во время его установки была проведена обработка верхнего и нижнего трещиноватых оснований. Сложные условия, которые включали низкое качество грунта и разрушенное морозом основание, требовали применения комбинированного решения для обеспечения быстрого затвердевания и достижения целевой глубины экрана. Дополнительные проблемы, которые были решены, включали ограниченные объемы раствора и необходимость непрерывного мониторинга окружающей среды.

Сотрудниками нескольких канадских технологических компаний проведено исследование по созданию противофильтрационных преград для дамб на основе карбонатных горных пород [54]. Представлен обзор подходов к проектированию и конструированию различного рода завес для устранения фильтрации, исследованы их эксплуатационные характеристики. Опыт создания бетонных завес в твердых горных породах с высокой степенью проницаемости побудил исследователей создать композитную завесу. На этапе подготовительных работ в зонах с высокой проницаемостью вначале проводилось высококачественное бурение, испытания на проницаемость и цементация для герметизации трещин, а также детально исследовалась геологическая основа для последующего определения локации и протяженности будущей противофильтрационной бетонной завесы. Показано, что концепция «композитной стены» своевременна и экономически эффективна в сравнении с другими дорогостоящими подходами.

Решению проблем фильтрации вод на бетонной плотине des Quinze Dam, расположенной в канадской провинции Квебек, посвящено исследование [55]. Для снижения утечки были предприняты многочисленные подходы к цементации. Первоначальная цементация была завершена основными цементно-водными растворами с последующей цементацией с добавлением тиксотропного агента Celbex. Окончательная цементация проводилась в несколько этапов малоподвижными (low mobility grouting - LMG) и сбалансированными стабильными растворами высокой подвижности (high mobility grouting - HMG) с использованием полиуретанового раствора и силиката натрия для контроля схватывания. Данная программа выполнялась в зимних условиях, требующих специального оборудования и техники.

Проблемы при создании противофильтрационной стены с применением метода струйной цементации на дамбе John Hart North Earthfill Dam в канадской провинции Британская Колумбия рассмотрены в исследовании [56]. Чтобы обеспечить дополнительную защиту 70-летней плотины, компания ВС Hydro занялась возведением дополнительной противофильтрационной стены в северной части дамбы, используя технологию струйной цементации, где высокоскоростная струйная смесь подается под высоким давлением (от 300 до 500 бар) для размывания почвы с ее одновременным смешиванием с раствором. Основная проблема заключалась в поддержании высокого давления во время возведения стены. В работе описаны процедуры струйной цементации, состав используемой смеси, результаты полевых испытаний, а также меры по обеспечению безопасности и охраны окружающей среды.

Технология струйной цементации, ее преимущества перед другими мерами предотвращения фильтрации, а также несколько примеров конкретного применения данного подхода подробно изложены в работе сотрудников американской компании Schnabel Foundation Company [57]. Особенности использования струйного цементирования при создании противофильтрационных завес также описаны специалистами международной группы компаний по геотехническим решениям Keller Group [46]. Отмечается, что решение проблемы фильтрации на существующих плотинах с использованием технологии струйной цементации делает этот подход все более экономически выгодной альтернативой другим методам. Авторы приводят краткое описание технологии, фокусируясь на технических аспектах, важных на этапах проектирования и восстановления дамб. Также приводится список дамб, успешно использующих данную технологию.

Представляют определенный интерес работы сотрудников Университета Калгари из канадской провинции Альберта, демонстрирующих преимущества технологии нагнетания противофильтрационной завесы в каменных сооружениях, расположенных в холодных климатических условиях $[47,48]$. При создании противофильтрационной завесы использовался метод моделирования «латинский гиперкуб» в сочетании с параметрической моделью с конечным числом элементов для рандомизации свойств материала каждого камня и соответствующих слоев цементации. Вопросы оптимального расположения оси дамбы в сочетании с вопросами обеспечения снижения проницаемости грунта и проектирования противофильтрационной завесы изучены в работе [58]. 
Метод создания полимерной ультратонкой противофильтрационной стены описан в патенте [59] и включает следующие этапы: формирование непрерывных слотов на участках дамбы, требующих усиления и защиты от фильтрации; впрыскивание двухкомпонентных расширяющихся полимерных тампонажных материалов в прорези. Объем быстро расширяется, после того как полимерные тампонажные материалы вступают в реакцию, и прорези заполняются, формируя полимерную ультратонкую основу. Смежные сверхтонкие полимерные основы совместно цементируются, образуя непрерывную и однородную зацементированную ультратонкую полимерную противофильтрационную стену. Преимущества такого подхода, рекомендуемого для укрепления дамб, заключаются в быстроте строительства, ультратонкости, легкости, высокой прочности, экономичности и долговечности.

Существенный интерес к снижению фильтрационных потоков на дамбах в условиях холодного климата проявляют исследователи из Китая, высокогорные регионы которого имеют схожие с Россией условия холодного климата и вечной мерзлоты. Например, в работе [60] описана технология создания бетонного экрана на каменно-набросных и песчано-гравийных дамбах высотой более 100 м в Синьцзяне. Показаны инновационные достижения в плане проектирования плотины с защитой от сейсмических событий, деформаций и фильтрации. Задача создания горизонтальной пластмассовой дрены в дамбах на вечномерзлых грунтах Тибетского нагорья рассматривается в работе [61].

Задача снижения фильтрационного потока в вечномерзлых грунтах Тибетского нагорья также решается в работе [62], где авторы предлагают собственную технологию заполнения слоя разорванной каменной породы, одновременно решая задачу защиты слоя мерзлого грунта от размораживания. Проблема двойственного характера, включающая теплопередачу и фильтрацию, решена с применением математических методов Галеркина и Кранка-Николсона, а также представлено соответствующее программное обеспечение.

На примере дамбы Вудонгде, расположенной в Китае, проанализированы значимые при возведении противофильтрационной завесы геологические факторы, включая карст, брекчии, структурную плоскость, разлом, угол пересечения между завесой и группой горных пород [49]. В соответствии с характеристиками различных геологических факторов были предложены оптимальные методы заполнения тампонажным раствором и динамической регулировки давления тампонажного материала.

В работе [63] на примере дамб каменнонабросного типа рассмотрены вопросы создания противофильтрационных преград вертикального, горизонтального и комбинированного типов. Описаны технологии возведения противофильтрационных бетонных стен и завес, а также технологии горизонтального покрытия. В численном моделировании фильтрационного контроля дамбы авторы прибегают к методам конечных элементов (finite element method-FEM) и методам граничных элементов (boundary element method - BEM), которые были применены в трех конкретных инженерных проектах. Даны предложения по контролю фильтрационных вод на дамбах каменно-набросного типа.

Отдельное внимание исследователи уделяют свойствам и характеристикам растворов для создания противофильтрационных завес. Так, в работе ученых из канадского Университета западного Онтарио рассмотрены механические и гидравлические свойства пластичного бетона (PL-C) для противофильтрационных завес [64]. Пластичный бетон используется при строительстве противофильтрационных завес в дамбах и содержит цемент, заполнитель и воду, смешанные с бентонитом натрия. Добавление бентонита натрия приводит к снижению прочности и повышению пластичности после разрушения по сравнению с обычным бетоном. Механические свойства пластичного бетона исследованы в серии испытаний на неограниченное сжатие и на сжатие в ограниченном объеме, проводимых с одновременной фильтрацией воды через опытные образцы. Результаты испытаний показали, что гидравлическая проводимость пластичного бетона возрастает от двух до трех порядков во время трехосного сжатия из-за образования трещин и их расширения. Показано, что такие деформации необходимо свести к минимуму на этапах проектирования путем контроля рабочих напряжений и использования устойчивых к эрозии смесей.

В работе американских исследователей из компании Sovereign International, производящей полимерные растворы, описаны технология использования и рабочие характеристики полимерной эмульсии для создания плотных и гибких противофильтрационных конструкций [65]. Демонстрируется экономическая эффективность использования подобных эмульсий.

В исследовании [66] обращается внимание на несовершенство современных технологий, призванных предотвращать фильтрацию на дамбах хвостохранилищ горнорудных предприятий, и на необходимость комплексного подхода к решению этой проблемы. Исследователями разработана технология создания не вступающего в реакцию с водой химически устойчивого полимерного раствора для строительства противофильтрационных преград на дамбах хвостохранилищ. Результаты испытаний показали, что технология использования предложенной полимерной стены вызывала незначительные нарушения в дамбе хвостохранилища, обладала хорошими противофильтрационными характеристиками и продемонстрировала долговечность.

\section{Заключение}

Основные технические решения по контролю и предотвращению фильтрации из хвостохранилищ горно-обогатительных предприятий включают мероприятия по управлению температурным режимом грунтов, противофильтрационные экраны и завесы, 
тампонажные технологии предотвращения фильтрации вод через плотины и прилегающий горный массив в условиях вечной мерзлоты.

Мероприятия по управлению температурным режимом грунтов включают: математическое моделирование теплообменных процессов, использование сезоннодействующих охлаждающих устройств, системы теплоизолирующих труб для водоотведения и отведение тепла при помощи тепловых насосов.

Противофильтрационные экраны создаются путем бурения наклонных скважин с последующей проморозкой естественным холодом, устройства защитных берм с применением послойного намораживания вскрышных пород и защитного покрытия для предотвращения растепления при помощи влаго-, тепло- и светоотражающего мата. При создании противофильтрационных экранов на мерзлых грунтах в районах сезонного уровня промерзания грунта ниже глубины укладки противофильтрационного экрана обосновывается применение бентонитовых матов. Мерзлотные завесы на основе парожидкостных энергонезависимых систем или индивидуальных термостабилизаторов используются для сохранения герметичности экрана при температурах до $-50-60{ }^{\circ} \mathrm{C}$.

Основные освещенные в литературе тампонажные технологии предотвращения фильтрации вод через

\section{СПИСОК ЛИТЕРАТУРЫ}

1. Оценка кислотообразующего/кислотонейтрализующего потенциалов отвальных пород и подвижности потенциально токсичных элементов Раздолинского рудного узла (Красноярский край) / С.Б. Бортникова, Н.В. Силантьева, А.Н. Запольский, Н.В. Юркевич, О.П. Саева, А.Я. Шевко, О.В. Шуваева, А.В. Еделев // Известия Томского политехнического университета. Инжиниринг георесурсов. - 2018. - Т. 329. - № 12.C. 55-72.

2. Корнеева Т.В., Юркевич Н.В., Аминов П.Г. Геохимические особенности миграционных потоков в зоне влияния горнопромышленного техногенеза (г. Медногорск) // Известия Томского политехнического университета. Инжиниринг георесурсов. - 2017. - Т. 328. - № 2. - С. 85-94.

3. Корнеева Т.В., Юркевич Н.В., Саева О.П. Геохимическое моделирование поведения тяжелых металлов в техногенных системах // Известия Томского политехнического университета. Инжиниринг георесурсов. - 2018. - Т. 329. - № 3.C. $89-101$.

4. Geophysical investigations for evaluation of environmental pollution in a mine tailings area / N.V. Yurkevich, N.A. Abrosimova, S.B. Bortnikova, Y.G. Karin, O.P. Saeva // Toxicological \& Environmental Chemistry. - 2017. - V. 99. - № 9-10. - P. 1328-1345.

5. Kotsemir M., Shashnov S. Measuring, analysis and visualization of research capacity of university at the level of departments and staff members // Scientometrics. - 2017. - V. 112. - № 3.P. 1659-1689.

6. Базоев Х.А., Волянский И.В., Бутюгин В.В. Геоэкологические аспекты эксплуатации хвостохранилищ в зоне вечной мерзлоты // Обогащение руд. - 2006. - № 6. - С. 39-41.

7. Базоев Х.А., Волянский И.В., Бутюгин В.В. Основные принципы обеспечения фильтрационной устойчивости хвостохранилищ в северных регионах // Обогащение руд. - 2006.№ 5. - C. 39-42.

8. Лолаев А.Б., Бутюгин В.В. Накопители отходов рудообогащения в условиях Крайнего Севера. Проблемы и пути решения // Ресурсовоспроизводящие, малоотходные и природоохранные технологии освоения недр: Материалы 2 Международной конференции. - М., 15-18 сентября 2003. - М.: Изд-во РУДН, 2003. - C. 265-270. плотины и прилегающий горный массив в условиях вечной мерзлоты включают использование растворов на основе тампонажного портландцемента, облегчающих добавок (например, алюмосиликатные микросферы), расширяющего компонента и жидкости затворения (например, раствор хлористого кальция); тампонажных смесей на основе гипса, бруситового каустического порошка, сернокислого магния, торфа.

Перспективным направлением в разработке противофильтрационных мероприятий на предприятиях, расположенных в районах Севера и вечной мерзлоты, является использование криогелей, создающих завесу, которая упрочняется при замораживании и оттаивании.

Анализ публикаций за период с 2000 г. по настоящее время показал, что, несмотря на актуальность проблемы утечек фильтрационных вод на хвостохранилищах горнодобывающих предприятий, отмечается ограниченность опубликованных разработок и недостаток технической литературы по этому направлению.

Исследование выполнено по программам ФНИ 0266-2019-0008 и IX.128.1, при частичной финансовой поддержке РФФИ в рамках научного проекта 19-011-00531.

9. Технологические особенности строительства грунтовых плотин дражных полигонов в условиях россыпного месторождения криолитозоны / А.М. Бураков, С.А. Ермаков, М.В. Каймонов, А.С. Курилко, Ю.А. Хохолов // Горный информационноаналитический бюллетень. - 2006. - № 8. - С. 271-276.

10. Формирование выемочного пространства россыпных месторождений криолитозоны / С.А. Ермаков, А.С. Курилко, А.М. Бураков, М.В. Каймонов, Ю.А. Хохолов // Горный информационно-аналитический бюллетень. - 2008. - № 10. - С. 63-69.

11. Способ возведения насыпных низконапорных плотин мерзлого типа в климатических условиях севера Якутии / А.С. Чаадаев, М.А. Комаров, С.Н. Долгих, И.А. Максимов // Горный журнал. - 2012. - № 4. - С. 50-53.

12. Опыт эксплуатации хвостохранилищ в Норильском промышленном районе / В.В. Бутюгин, М.С. Скачков, Е.А. Гулан, Б.С. Пыхтин, В.А. Конев // Горный журнал. - 2004. - № 5. С. 54-58.

13. Кузнецов Г.И. Накопители промышленных отходов в зоне вечной мерзлоты // Известия высших учебных заведений. Строительство. - 2015. - № 4. - С. 65-80.

14. Кузнецов Г.И., Балацкая Н.В. Экологически безопасные накопители промышленных отходов на Крайнем Севере // Экологические системы и приборы. - 2013. - № 3. - С. 38-46.

15. Система улавливания стоков из хвостохранилищ на вечномерзлых грунтах: пат. РФ № 2223362; рег. № заявки изобр. 2001127345/13, заявл. 08.10.2001, опубл. 10.02.2004.

16. Романова Е.К., Курилко А.С., Киселев В.В. Управление устойчивостью уступов кимберлитовых карьеров криолитозоны с помощью теплоизолированного оградительного сооружения // Горный информационно-аналитический бюллетень. 2017. - № S24 - C. 264-271.

17. Analysis of the operating capacity of seasonally functioning cooling devices using operational data of waterworks facilities / N.A. Buchko, I.A. Maksimov, M.P. Pavchich, V.A. Turchina // Power Technology and Engineering. - 2004. - V. 38. - № 2. P. 65-70.

18. Надпакерная жидкость на углеводородной основе для предотвращения растепления мерзлых пород / Ж.С. Попова, Д.А. Небогин, Р.В. Плаксин, Н.В. Козлова, И.Н. Кустышева // Строительство нефтяных и газовых скважин на суше и на моpe. -2012 . - № 1. - C. 27-31. 
19. Гелисханов А.Б. Применение теплоизолирующих труб для изоляции зон ММП при строительстве скважин на Уренгойской группе месторождений // Геология и нефтегазоносность Западно-Сибирского мегабассейна (опыт, инновации): Материалы 8 Всероссийской научно-практической конференци, посвященной 100-летию со дня рождения В.И. Муравленко. Тюмень, 24 декабря 2012. - Т. 1. - С. 37-38.

20. Долгих Г.М., Окунев С.Н., Стрижков С.Н. Опыт термостабилизации грунтов устьев нефтяных и газовых скважин с использованием систем ВЕТ // Нефтяное хозяйство. - 2012. № 3. - C. $80-82$.

21. Система «ВЕТ» - современное техническое решение для температурной стабилизации грунтов устьев нефтегазовых скважин // Газовая промышленность. - 2016. - № 3. - С. 112-113.

22. Способ защиты уступов бортов карьеров криолитозоны от растепления: пат. РФ № 2551583; заявл. 20.02.2014, опубл. 27.05.2015.

23. Проблемы устройства противофильтрационных экранов на мерзлых и вечномерзлых грунтах / В.А. Яковлев, Е.С. Круглова, О.А. Ильина, Е.В. Баранихин // Реагенты и материалы для строительства, эксплуатации и ремонта нефтяных, газовых и газовоконденсатных скважин: производство, свойства и опыт применения. Экологические аспекты нефтегазового комплекса: Материалы 20 Международной научно-практической конференции. - Суздаль, 7-10 июня 2016. - С. 139-141.

24. Гулан Е.А. Обеспечение экологической безопасности гидротехнических сооружений в криолитозоне // Ресурсовоспроизводящие, малоотходные и природоохранные технологии освоения недр: Материалы 7 Международной конференции. - М.Ереван, 15-19 сентября 2008. - М.: РУДН, 2008. - С. 305-306.

25. Долгих Г.М., Окунев С.Н., Стрижков С.Н. Ледяной экран для полигона на Крайнем Севере // Твердые бытовые отходы. 2011. - № 11. - С. 17-19.

26. Долгих Г.М., Окунев С.Н., Стрижков С.Н. Экотехнологии и оборудование: внедрение инновационных экологически чистых технологий при утилизации ТБО в криолитзоне // Экологический вестник России. - 2012. - № 1. - С. 29-33.

27. Способ защиты горных выработок от прорыва воды со стороны водотока в условиях вечной мерзлоты: пат. РФ № 2394962; заявл. 20.05.2009, опубл. 20.07.2010.

28. Орешкин Д.В., Фролов А.А., Ипполитов В.В. Проблемы теплоизоляционных тампонажных материалов для условий многолетних мерзлых пород. - М.: Недра-Бизнесцентр, 2004. - 236 с.

29. Облегченный тампонажный цемент для низкотемпературных скважин / В. Овчинников, В. Кузнецов, А. Фролов, Ю. Газгиреев // Бурение и нефть. - 2004. - № 5. - С. 32-33.

30. Орешкин Д.В. Облегченные и сверхлегкие тампонажные растворы для крепления нефтегазовых скважин // Строительство нефтяных и газовых скважин на суше и на море. - 2010. № 10. - С. 34-36.

31. Орешкин Д.В., Близнюков В.Ю. Современные тенденции разработки универсальных сверхлегких тампонажных растворов для условий АНПД и ММП // Строительство нефтяных и газовых скважин на суше и на море. - 2007. - № 2. - С. 49-56.

32. Сырьевая смесь для получения теплозащитного тампонажного материала для условий многолетних мерзлых пород: пат. РФ № 2267004; заявл. 31.10.2003, опубл. 27.12.2005.

33. Орешкин Д.В., Янкевич В.Ф., Первушин Г.Н. Проблемы крепления стенок при строительстве нефтяных и газовых скважин // Строительство нефтяных и газовых скважин на суше и на море. -2002 . - № 7-8. - С. 43-46.

34. Сырьевая смесь для получения облегченного тампонажного раствора: пат. РФ № 2472835; заявл. 01.07.2011, опубл. 20.01.2013.

35. Медведев Ю.В. Эффективное решение для тампонирования скважин в новых нефтепромысловых районах // Нефть. Газ. Новации. - 2013. - № 3. - С. 38-40.

36. Речапов Д.А., Коростелев А.С., Кузнецов В.Г. Эффективность применения арктических тампонажных систем в интервалах залегания мерзлых пород // Труды 10 Международной конференции по мерзлотоведению (ТІСОР 2012). - Салехард, 25-29 июня 2012. - Т. 5. - С. 261.

37. Яковлев А.А. Анализ условий надежного тампонирования скважин газожидкостными тампонажными смесями // Записки Горного института. - 2012. - Т. 197. - С. 71-74.
38. Тампонажный материал: пат. РФ № 2460754; заявл. 30.03.2011, опубл. 10.09.2012.

39. Расширяющийся тампонажный состав для низкотемпературных скважин: пат. РФ № 2155263; заявл. 15.01.1998, опубл. 27.08.2000.

40. Орешкин Д.В., Первушин Г.Г. Изменение влажности и теплопроводности цементного тампонажного камня с полыми стеклянными микросферами во времени // Строительство нефтяных и газовых скважин на суше и на море. - 2003. - № 2. C. $41-43$.

41. Оценка сохранности защитного покрытия хвостохранилища рудника Кумтор (Кыргызская Республика) на основе решения обратной задачи по данным измерения давления в наблюдательных скважинах / Л.А. Назарова, Л.А. Назаров, А.В. Панов, Н.А. Мирошниченко, М.К. Чыныбаев // Вестник КыргызскоРоссийского славянского университета. - 2017.- Т. 17.№ 1. - C. 34-37.

42. Evolution of thermohydrodynamic fields at tailings dam at Kumtor mine (Kyrgyz Republic) / L.A. Nazarova, L.A. Nazarov, M.D. Dzhamanbaev, M.K. Chynybaev // Journal of Mining Science. - 2015. - V. 51. - № 1. - P. 17-22.

43. Buiskikh A.A., Zamoshch M.N. Prediction of thermal regime within a tailing dump under permafrost // Journal of Mining Science. - 2010. - V. 46. - № 1. - P. $28-33$.

44. Алешин Ю.Г., Торгоев И.А., Чукин Б.А. Риски на участках заложения высокогорных хвостохранилищ (внутренний ТяньШань): идентификация в процессе эксплуатации // Проблемы снижения природных опасностей и рисков: Материалы Международной научно-практической конференции «Геориск2012». - М., 18-19 октября 2012. - Т. 2. - С. 6-14.

45. Khrustalev L.N. Analysis of the warming of frozen soil around a cooling column after its disconnection // Soil Mechanics and Foundation Engineering. - 2001. - V. 38. - № 2. - P. 69-73.

46. Jet grouting to construct a seepage cutoff around a spillway / M.C. Canino, C.H. Starling Iii, W.K. Endo, J. Gault // Association of State Dam Safety Officials - Dam Safety 2006, Proceedings from the 2006 Annual Conference. - 2006. - P. 220-239.

47. Isfeld A.C. Numerical modelling of grout injection in stone masonry walls // Masonry International. - 2016. - V. 29. - № 3.P. 73-84.

48. Uncertainty analysis of the effect of grout injection on the deformation of multi-wythe stone masonry walls / A.C. Isfeld, E. Moradabadi, D.F. Laefer, N.G. Shrive // Construction and Building Materials. - 2016. - V. 126. - P. 661-672.

49. Geological factors and its treatment measures of dams antiseepage grouting curtain at Wudongde hydropower station / J. Xiang, T. Wang, K. Ni, L. Wan, Y. Shi, W. Hu // Journal of Jilin University (Earth Science Edition). - 2018. - V. 48. - № 5.P. $1581-1588$

50. Mine tailings dams: characteristics, failure, environmental impacts, and remediation / D. Kossoff, W.E. Dubbin, M. Alfredsson, S.J. Edwards, M.G. Macklin, K.A. Hudson-Edwards // Applied Geochemistry. - 2014. - V. 51. - P. 229-245.

51. Design and construction of a seepage cut off wall using the slurry trench technique in cold temperatures at the Horizon Dam project / L.A. Barr, J.C. Sobkowicz, C. Kwok, R. Armstrong, J. Henderson // Canadian Geotechnical Conference. - 2010. - V. 63. - P. 735-741.

52. Joshi P., McLeod H. Effectiveness of geomembrane liners in minimizing seepage in tailings storage facilities - New knowledge $/ / 26^{\text {th }}$ International Congress on Large Dams. - Vienna, Austria, 4-6 July, 2018. - P. 368-381

53. Rombough V.T., Davies J.A., Hoy J.P. Grout curtain installation for sump excavation in permafrost region of Northern Canada // Geotechnical Special Publication. - 2017. - P. 106-115.

54. Bruce D.A., Dreese T.L., Heenan D.M. Design, construction, and performance of seepage barriers for dams on carbonate foundations // Environmental and Engineering Geoscience. - 2010.V. 16. - № 3. - P. 183-193.

55. Mixed grouting methods and materials for under-seepage mitigation at Barrage des Quinze Dam, Quebec, Canada / M.J. Byle, D. Dery-Chamberland, P. Bowman, M. Dubeau // Geotechnical Special Publication. - 2017. - P. 58-66.

56. Gazzarrini P., Siu D., Jungaro S. Construction of a jet-grouted backup seepage cut-off wall in the John Hart North Earthfill Dam // Geotechnical Special Publication. - 2017. - P. 92-101. 
57. Niermann M.J., Jenevein D.R., Worst S.L. Jet grouting for water cutoff and excavation support // Geotechnical Special Publication. - 2017. - P. 124-134.

58. Canoglu M.C. Selection of suitable dam axis location considering permeability and grout curtain optimization // Environmental and Engineering Geoscience. - 2019. - V. 25. - № 1. - P. 15-25.

59. Polymer grouting method for constructing ultra-thin anti-seepage wall: pat. USA № 20140314498; published 23.10.2014.

60. Deng M.J. Advances in key technology for concrete face dams with deep overburden layers under cold and seismic conditions // Chinese Journal of Geotechnical Engineering. - 2012. - V. 34. № 6. - P. 985-996.

61. Test and mechanism of horizontal plastic drain in permafrost regions embankment / J.H. Hu, R. Wang, M.J. Hu, K.P. Zhou // Zhongnan Daxue Xuebao (Ziran Kexue Ban)/Journal of Central South University (Science and Technology). - 2009. - V. 40.№ 5. - P. 1451-1456.

62. Xuefu Z., Yaonan Z. Study on a new-styled measure for treating water leakage of the permafrost tunnels // Tunnelling and Underground Space Technology. - 2006. - V. 21. - № 6. - P. 656-667.
63. Shen Z., Qiu L., Zhou H. Review of seepage control of earthrockfill dams on thick overburden layer // Advances in Science and Technology of Water Resources. - 2015. - V. 35. - № 5. P. 27-35.

64. Hinchberger S., Weck J., Newson T. Mechanical and hydraulic characterization of plastic concrete for seepage cut-off walls // Canadian Geotechnical Journal. - 2010. - V. 47. - № 4. - P. 461-471.

65. Polymer emulsion grouting for water cutoff in tunnel structures / P.M. Gancarz, J.E. Minturn, N.J. Grobler, D. Van Dyk // Geotechnical Special Publication. - 2017. - P. 295-302.

66. Guo C., Chu X., Wang F. The feasibility of non-water reaction polymer grouting technology application in seepage prevention for tailings reservoirs // Water Science and Technology: Water Supply. - 2018. - V. 18. - № 1. - P. 203-213.

Поступила 13.03.2020 2.

\section{Информация об авторах}

Юркевич Н.В., кандидат технических наук, заведующий лабораторией эколого-экономического моделирования техногенных систем, Институт нефтегазовой геологии и геофизики им. А.А. Трофимука СО РАН.

Юркевич Н.В., кандидат геолого-минералогических наук, заведующий лабораторией гидрохимии, Институт нефтегазовой геологии и геофизики им. А.А. Трофимука СО РАН.

Гуреев В.Н., кандидат педагогических наук, старший научный сотрудник информационно-аналитического центра, Институт нефтегазовой геологии и геофизики им. А.А. Трофимука СО РАН; Новосибирский государственный технический университет.

Мазов Н.A., кандидат технических наук, заведующий информационно-аналитическим центром, Институт нефтегазовой геологии и геофизики им. А.А. Трофимука СО РАН. 
UDC 624.136:551.345

\title{
PROBLEMS OF CONTROLLING WATER FILTRATION IN HYDRAULIC STRUCTURES IN PERMAFROST REGIONS
}

\author{
Nikolay V. Yurkevich ${ }^{1}$, \\ YurkevichNV2@ipgg.sbras.ru \\ Natalia V. Yurkevich ${ }^{1}$, \\ YurkevichNV@ipgg.sbras.ru \\ Vadim N. Gureyev1,2, \\ GureyevVN@ipgg.sbras.ru \\ Nikolay A. Mazov ${ }^{1}$, \\ MazovNA@ipgg.sbras.ru \\ 1 Trofimuk Institute of Petroleum Geology and Geophysics, SB RAS, \\ 3, Koptyug avenue, Novosibirsk, 630090, Russia. \\ 2 Novosibirsk State Technical University, \\ 136, Nemirovicha-Danchenko street, Novosibirsk, 630087.
}

The relevance of the research is caused by the environmental risks in relation to the technogenic thawing of permafrost soils in the waste storage sites of mining enterprises in the Far North.

The main aim of the research is the analysis of world experience on the problems of the permafrost degradation, the filtration channels in fractured tectonic zones development, which cause leakage of circulating water from tailings of mining and processing enterprises, and the search for technological solutions aimed at reducing the filtration flow and preventing environmental problems.

Methods: retrospective analysis of publications selected as a result of a search in domestic and international bibliographic databases, including the abstract journal VINITI RAS, Russian Science Citation Index and Scopus bibliographic index from Elsevier, from 2000 to the present. Results. Controlling filtration in tailing dams in permafrost conditions is primarily carried out using management of thermal cycles of soils, constructing anti-seepage screens and curtains, as well as using grouting techniques. The main approaches described in research literature include the use of solutions of artificial cement, lightweights (aluminocilicate microspheres), expanding component and tempering fluids (calcium chloride solution); gypsum-based grouting mixtures, brucite caustic solution, magnesium sulphate, and turf. The use of cryogels constructing a screen that become firmer during freezing-thawing cycles is another promising technique in designing anti-seepage constructions in North and permafrost regions. The analysis of publications from 2000 to the present has shown that despite the urgency of the mine drainage problem, there is a limitation of published research and a lack of technical literature in this area.

\section{Key words:}

Permafrost, thawing soils, hydraulic structures, dyke, embankment, tailing dam, review.

The reported study was carried out in the framework of the Fundamental Research Programs (nos. IX.128.1, 0266-2019-0008) and partly funded by RFBR according to the research project no. 19-011-00531.

\section{REFERENCES}

1. Bortnikova S.B., Silantyeva N.V., Zapolsky A.N., Yurkevich N.V., Saeva O.P., Shevko A.Y., Shuvaeva O.V., Edelev A.V. Assessment of acidbase accounting of mine waste rocks and mobility of potentially toxic elements of the Razdolinsky ore field (Krasnoyarsk Territory). Bulletin of the Tomsk Polytechnic University. Geo Assets Engineering, 2018, vol. 329, no. 12, pp. 55-72. In Rus.

2. Korneeva T.V., Yurkevich N.V., Aminov P.G. Geochemical features of migration flows in the impact zone of mining technogenesis (Mednogorsk). Bulletin of the Tomsk Polytechnic University. Geo Assets Engineering, 2017, vol. 328, no. 2, pp. 85-94. In Rus.

3. Korneeva T.V., Yurkevich N.V., Saeva O.P. Geochemical modeling of heavy metals behavior in technogenic systems. Bulletin of the Tomsk Polytechnic University. Geo Assets Engineering, 2018, vol. 329, no. 3, pp. 89-101. In Rus.

4. Yurkevich N.V., Abrosimova N.A., Bortnikova S.B., Karin Y.G., Saeva O.P. Geophysical investigations for evaluation of environmental pollution in a mine tailings area. Toxicological \& Environmental Chemistry, 2017, vol. 99. no. 9-10, pp. 1328-1345.

5. Kotsemir M., Shashnov S. Measuring, analysis and visualization of research capacity of university at the level of departments and staff members. Scientometrics, 2017, vol. 112, no. 3, pp. $1659-1689$.
6. Bazoev Kh.A., Volyanskiy I.V., Butyugin V.V. Geoekologicheskie aspekty ekspluatatsii khvostohranilishch $\mathrm{v}$ zone vechnoy merzloty [Geoecological aspects of tailings disposal systems operation in permafrost zone]. Obogashchenie Rud, 2006, no. 6, pp. 39-41.

7. Bazoev Kh.A., Volyanskiy I.V., Butyugin V.V. Osnovnye printsipy obespecheniya filtratsionnoy ustoychivosti khvostohranilishch v severnykh regionakh [Main principles of providing tailings storage facilities seepage stability in northern regions]. Obogashchenie Rud, 2006, no. 5, pp. 39-42.

8. Lolaev A.B., Butyugin V.V. Nakopiteli otkhodov rudoobogashcheniya v usloviyakh Kraynego Severa. Problemy i puti resheniya [Tailing ponds at ore cleaning sites at the Far North. Problems and solutions]. Resursovosproizvodyashchie, malootkhodnye i prirodookhrannye tekhnologii osvoeniya nedr. Materialy 2 mezhdunarodnoy konferentsii [Resource reproductive, low waste and nature saving techniques of exploitation. Materials of the $2{ }^{\text {nd }}$ International conference]. Moscow, 15-18 September 2003. pp. 265-270.

9. Burakov A.M., Ermakov S.A., Kaymonov M.V., Kurilko A.S., Khokholov Yu.A. Tekhnologicheskie osobennosti stroitelstva gruntovykh plotin drazhnykh poligonov v usloviyakh rossypnogo mestorozhdeniya kriolitozony [Technological features of building of earth dams in the grounds under conditions of placers of cryolitic zones]. Gorny informatsionnoanaliticheskiy byulleten, 2006, no. 8, pp. 271-276. 
10. Ermakov S.A., Kurilko A.S., Burakov A.M., Kaymonov M.V., Hokholov Yu.A. Formirovanie vyemochnogo prostranstva rossypnykh mestorozhdeniy kriolitozony [Formation of winning space in placer mines in cryolitic zomes]. Gorny informatsionno-analiticheskiy byulleten, 2008, no. 10, pp. 63-69.

11. Chaadaev A.S., Komarov M.A., Dolgikh S.N., Maksimov I.A Sposob vozvedeniya nasypnykh nizkonapornykh plotin merzlogo tipa v klimaticheskikh usloviyakh severa Yakutii [The way of building the poured low pressure frozen type dams in the climate conditions of the north of Yakutia]. Gornyi Zhurnal, 2012, no. 4, pp. 50-53.

12. Butyugin V.V., Skachkov M.S., Gulan E.A., Pyhtin B.S., Konev V.A. Opyt ekspluatatsii khvostohranilishch v Norilskom promyshlennom rayone [The influence of natural and mancaused factors on stability of constructions located in cryolite area is analyzed]. Gornyi Zhurnal, 2004, no. 5, pp. 54-58.

13. Kusnetsov G.I. Nakopiteli promyshlennykh otkhodov v zone vechnoy merzloty [Stores of industrial wastes in a permafrost zone]. Izvestiya vysshikh uchebnykh zavedenij. Stroitelstvo, 2015, no. 4, pp. 65-80.

14. Kuznetsov G.I., Balatskaya N.V. Ekologicheski bezopasnye nakopiteli promyshlennykh othodov na Kraynem Severe [Ecologically safe stores of industrial wastes on the Far North]. Ekologicheskie sistemy i pribory, 2013, no. 3, pp. 38-46.

15. Babello V.A., Petrov V.S., Belyakov A.E. Sistema ulavlivaniya stokov iz khvostohranilishch na vechnomerzlykh gruntakh [System of capture of flows from tailing dams in permafrost rocks]. Patent RF no. 2223362, 2004.

16. Romanova E.K., Kurilko A.S., Kiselev V.V. Upravlenie ustoychivostyu ustupov kimberlitovykh karerov kriolitozony s pomoshchyu teploizolirovannogo ograditelnogo sooruzheniya [Management of stability of benches in cryolitic zones using heat insulated protective construction]. Gorny informatsionnoanaliticheskiy byulleten, 2017, no. S24, pp. 264-271.

17. Buchko N.A., Maksimov I.A., Pavchich M.P., Turchina V.A. Analysis of the operating capacity of seasonally functioning cooling devices using operational data of waterworks facilities. Power Technology and Engineering, 2004, vol. 38, no. 2, pp. 65-70.

18. Popova Zh.S., Nebogin D.A., Plaksin R.V., Kozlova N.V., Kustysheva I.N. Nadpakernaya zhidkost na uglevodorodnoy osnove dlya predotvrashcheniya rastepleniya merzlykh porod [Packer fluid based on carbon hydrate for preventing thawing of frozen rocks]. Stroitelstvo neftyanykh i gazovykh skvazhin na sushe i na more, 2012, no. 1, pp. 27-31.

19. Geliskhanov A.B. Primenenie teploizoliruyushchikh trub dlya izolyatsii zon MMP pri stroitelstve skvazhin na Urengoyskoy gruppe mestorozhdeniy [The use of heat sealing pipes to isolate permafrost zones when building boreholes at Urengoy deposits]. Geologiya $i$ neftegazonosnost Zapadno-Sibirskogo megabasseyna (opyt, innovatsii). Materialy 8 Vserossiyskoy nauchnoprakticheskoy konferentsii, posvyashchennoy 100-letiyu so dnya rozhdeniya V.I. Muravlenko [Geology and oil and gas bearing capacity of Western Siberian megabassin (experience, innovations). Materials of the $8^{\text {th }}$ All-Russian scientific-practice conference dedicated to the 100 anniversary V.I. Muravlenko]. Tyumen, 24 December 2012. Vol. 1, pp. 37-38.

20. Dolgikh G.M., Okunev S.N., Strizhkov S.N. Opyt termostabilizatsii gruntov ustev neftyanykh i gazovykh skvazhin $\mathrm{s}$ ispolzovaniem sistem VET [Thermostabilization of oil and gas well heads soils with use of vertical naturally acting systems]. Neftyanoe khozyaystvo, 2012, no. 3, pp. 80-82.

21. Sistema «VET»- sovremennoe tekhnicheskoe reshenie dlya temperaturnoy stabilizatsii gruntov ustev neftegazovykh skvazhin [VET system - modern technique for temperature stabilization of rocks of collar of oil-and-gas wells]. Gazovaya promyshlennost, 2016, no. 3, pp. 112-113.

22. Kurilko A.S., Kiselev V.V., Romanova E.K., Akishev A.N Sposob zashchity ustupov bortov karerov kriolitozony ot rastepleniya [An approach to defense shelves of open pit sites against thawing in cryolitic zone]. Patent RF no. 2551583, 2015.

23. Yakovlev V.A., Kruglova E.S., Ilina O.A., Baranikhin E.V. Problemy ustroystva protivofiltratsionnykh ekranov na merzlykh i vechnomerzlykh gruntakh [Problems of constructing cut-off curtains in frozen and permafrost rocks]. Reagenty $i$ materialy dlya stroitelstva, ekspluatatsii i remonta neftyanykh, gazovykh $i$ gazovokondensatnykh skvazhin: proizvodstvo, svoystva i opyt primeneniya. Ekologicheskie aspekty neftegazovogo kompleksa. Materialy 20 Mezhdunarodnoy nauchno-prakticheskoy konferentsii [Agents and materials for construction, maintenance and repair of oil, gas and gas-condensate wells: production, features, and experiences of application. Ecological aspects of oil-and-gas complex. Materials of the $20^{\text {th }}$ International scientific and practice conference]. Suzdal, 7-10 June, 2016. pp. 139-141.

24. Gulan E.A. Obespechenie ekologicheskoy bezopasnosti gidrotekhnicheskikh sooruzheniy v kriolitozone [Providing ecological safety of hydraulic structures in cryolitic zone]. Resursovosproizvodyashchie, malootkhodnye $i$ prirodookhrannye tekhnologii osvoeniya nedr. Materialy 7 Mezhdunarodnoy konferentsii [Resource reproductive, low waste and nature saving techniques of exploitation. Materials of the $7^{\text {th }}$ International conference]. Moscow-Erevan, 15-19 September 2008. pp. 305-306.

25. Dolgikh G.M., Okunev S.N., Strizhkov S.N. Ledyanoy ekran dlya poligona na Kraynem Severe [Ice screen for traverse at the Far North]. Tverdye bytovye otkhody, 2011, no. 11, pp. 17-19.

26. Dolgikh G.M., Okunev S.N., Strizhkov S.N. Ekotekhnologii i oborudovanie: vnedrenie innovatsionnykh ekologicheski chistykh tekhnologiy pri utilizatsii TBO v kriolitzone [Ecotechnologies and equipment: the use of innovation pollution-free techniques when utilizing RSW in cryolitic zones]. Ekologicheskij vestnik Rossii, 2012, no. 1, pp. 29-33.

27. Troyan N.S. Sposob zashchity gornykh vyrabotok ot proryva vody so storony vodotoka $v$ usloviyakh vechnoy merzloty [Defence method for mining outputs against water breakthrough on the side of streamflow under permafrost conditions]. Patent RF no. 2394962, 2010.

28. Oreshkin D.V., Frolov A.A., Ippolitov V.V. Problemy teploizolyatsionnykh tamponazhnykh materialov dlya usloviy mnogoletnikh merzlykh porod [Problems of heat insulating grouting materials for permafrost rocks]. Moscow, Nedra-Biznestsentr Publ., 2004. $236 \mathrm{p}$

29. Ovchinnikov V., Kuznetsov V., Frolov A., Gazgireev Yu. Oblegchenny tamponazhny tsement dlya nizkotemperaturnykh skvazhin [Light grouting cement for low temperature boreholes]. Burenie i neft, 2004, no. 5, pp. 32-33.

30. Oreshkin D.V. Oblegchennye i sverkhlegkie tamponazhnye rastvory dlya krepleniya neftegazovykh skvazhin [Light and extralight grouting compounds for strengthening oil-and-gas wells]. Stroitelstvo neftyanykh i gazovykh skvazhin na sushe i na more, 2010, no. 10, pp. 34-36.

31. Oreshkin D.V., Bliznyukov V.Yu. Sovremennye tendentsii razrabotki universalnykh sverkhlegkikh tamponazhnykh rastvorov dlya usloviy ANPD i MMP [Modern trends when developing universal extralight grouting mixtures under APRP and permafrost conditions]. Stroitelstvo neftyanykh i gazovykh skvazhin na sushe i na more, 2007, no. 2, pp. 49-56.

32. Oreshkin D.V., Ippolitov V.V., Frolov A.A., Pervushin G.N. Syrevaya smes dlya polucheniya teplozashchitnogo tamponazhnogo materiala dlya usloviy mnogoletnikh merzlykh porod [Raw mixture for obtaining heat-protecting material for permafrost regions]. Patent RF no. 2267004, 2005.

33. Oreshkin D.V., Yankevich V.F., Pervushin G.N. Problemy krepleniya stenok pri stroitelstve neftyanykh i gazovykh skvazhin [Problems of wall lining when building oil-and-gas wells]. Stroitelstvo neftyanykh i gazovykh skvazhin na sushe i na more, 2002, no. 7-8, pp. 43-46.

34. Oreshkin D.V., Belyaev K.V., Semenov V.S., Kretova U.E., Makarenkova Yu.V. Syrevaya smes dlya polucheniya oblegchennogo tamponazhnogo rastvora [Raw mixture for obtaining light grouting composition]. Patent RF no. 2472835, 2013.

35. Medvedev Yu.V. Effektivnoe reshenie dlya tamponirovaniya skvazhin v novykh neftepromyslovykh rajonakh [Effective solution for well squeezing in newly discovered oil producing areas]. Neft. Gaz. Novatsii, 2013, no. 3, pp. 38-40.

36. Rechapov D.A., Korostelev A.S., Kuznetsov V.G. Effektivnost primeneniya arkticheskikh tamponazhnykh sistem $\mathrm{v}$ intervalakh zaleganiya merzlykh porod [Efficiency of application of Arctic grouting systems in frozen rocks gross intervals]. Trudy 10 Mezhdunarodnoy konferentsii po merzlotovedeniyu (TICOP 2012) [Materials of the $10^{\text {th }}$ International conference on permafrost study]. Salekhard, 25-29 June, 2012. Vol. 5, pp. 261. 
37. Yakovlev A.A. Analiz usloviy nadezhnogo tamponirovaniya skvazhin gazozhidkostnymi tamponazhnymi smesyami [Analysis of condition of effective grouting of wells with liquid-gas grouting mixtures]. Zapiski Gornogo instituta, 2012, vol. 197, pp. 71-74.

38. Tolkachev G.M., Shilov A.M., Kozlov A.S., Pastuhov A.M Tamponazhny material [Grouting material]. Patent RF no. 2460754, 2012.

39. Anisimov A.A., Simonenko L.I., Zlotnikov G.P., Pogorelov E.V., Gukasova N.M., Budovkina L.S. Rasshiryayushchiysya tamponazhny sostav dlya nizkotemperaturnykh skvazhin [Enhancing backfill composition for low temperature boreholes] Patent RF no. 2155263, 2000.

40. Oreshkin D.V., Pervushin G.G. Izmenenie vlazhnosti i teploprovodnosti tsementnogo tamponazhnogo kamnya s polymi steklyannymi mikrosferami vo vremeni [Change in moisture and thermal conductivity of cement with cavate glass microspheres over time. Stroitelstvo neftyanykh i gazovykh skvazhin na sushe i na more, 2003, no. 2, pp. 41-43.

41. Nazarova L.A., Nazarov L.A., Panov A.V., Miroshnichenko N.A., Chynybaev M.K. Otsenka sokhrannosti zashchitnogo pokrytiya khvostohranilishcha rudnika Kumtor (Kyrgyzskaya Respublika) na osnove resheniya obratnoy zadachi po dannym izmereniya davleniya $v$ nablyudatelnykh skvazhinakh [Estimate of integrity of resistant coating at the tailing storage of Kumtor mine (the Kyrgyz Republic) based on the inverse problem solution using the data of pressure survey in observation wells]. Vestnik Kyrgyzsko-Rossiyskogo slavyanskolo universiteta, 2017, vol. 17, no. 1, pp. 34-37.

42. Nazarova L.A., Nazarov L.A., Dzhamanbaev M.D., Chynybaev M.K. Evolution of thermohydrodynamic fields at tailings dam at Kumtor mine (Kyrgyz Republic). Journal of Mining Science, 2015, vol. 51, no. 1, pp. 17-22.

43. Buiskikh A.A., Zamoshch M.N. Prediction of thermal regime within a tailing dump under permafrost. Journal of Mining Science, 2010, vol. 46, no. 1, pp. 28-33.

44. Aleshin Yu.G., Torgoev I.A., Chukin B.A. Riski na uchastkakh zalozheniya vysokogornykh khvostohranilishch (vnutrenniy TyanShan): identifikatsiya $v$ protsesse ekspluatatsii [Risks at the sites of mountain tailing dams (inner Tien Shan): identification in the process of exploitation]. Problemy snizheniya prirodnykh opasnostey i riskov. Materialy Mezhdunarodnoy nauchno-prakticheskoy konferentsii «Georisk-2012» [Problems of reducing natural perils and risks. Proc. International scientific and practical conference]. Moscow, 18-19 October 2012. Vol. 2, pp. 6-14.

45. Khrustalev L.N. Analysis of the warming of frozen soil around a cooling column after its disconnection. Soil Mechanics and Foundation Engineering, 2001, vol. 38, no. 2, pp. 69-73.

46. Canino M.C., Starling Iii C.H., Endo W.K., Gault J. Jet grouting to construct a seepage cutoff around a spillway. Association of State Dam Safety Officials - Dam Safety 2006. Proceedings from the 2006 Annual Conference. 2006. pp. 220-239.

47. Isfeld A.C. Numerical modelling of grout injection in stone masonry walls. Masonry International, 2016, vol. 29, no. 3, pp. 73-84.

48. Isfeld A.C., Moradabadi E., Laefer D.F., Shrive N.G. Uncertainty analysis of the effect of grout injection on the deformation of multi-wythe stone masonry walls. Construction and Building Materials, 2016, vol. 126, pp. 661-672.

49. Xiang J., Wang T., Ni K., Wan L., Shi Y., Hu W. Geological factors and its treatment measures of dams anti-seepage grouting curtain at Wudongde hydropower station. Journal of Jilin University (Earth Science Edition), 2018, vol. 48, no. 5, pp. 1581-1588.

50. Kossoff D., Dubbin W.E., Alfredsson M., Edwards S.J., Macklin M.G., Hudson-Edwards K.A. Mine tailings dams: Character- istics, failure, environmental impacts, and remediation. Applied Geochemistry, 2014, vol. 51, pp. 229-245.

51. Barr L.A., Sobkowicz J.C., Kwok C., Armstrong R., Henderson J. Design and construction of a seepage cut off wall using the slurry trench technique in cold temperatures at the Horizon Dam project. Canadian Geotechnical Conference, 2010, vol. 63, pp. 735-741.

52. Joshi P., McLeod H. Effectiveness of geomembrane liners in minimizing seepage in tailings storage facilities - New knowledge. $26^{\text {th }}$ International Congress on Large Dams. Vienna, Austria, 4-6 July, 2018. pp. 368-381.

53. Rombough V.T., Davies J.A., Hoy J.P. Grout curtain installation for sump excavation in permafrost region of Northern Canada. Geotechnical Special Publication, 2017, pp. 106-115.

54. Bruce D.A., Dreese T.L., Heenan D.M. Design, construction, and performance of seepage barriers for dams on carbonate foundations. Environmental and Engineering Geoscience, 2010, vol. 16, no. 3, pp. 183-193.

55. Byle M.J., Dery-Chamberland D., Bowman P., Dubeau M. Mixed grouting methods and materials for under-seepage mitigation at Barrage des Quinze Dam, Quebec, Canada. Geotechnical Special Publication, 2017, pp. 58-66.

56. Gazzarrini P., Siu D., Jungaro S. Construction of a jet-grouted backup seepage cut-off wall in the John Hart North Earthfill Dam. Geotechnical Special Publication, 2017, pp. 92-101.

57. Niermann M.J., Jenevein D.R., Worst S.L. Jet grouting for water cutoff and excavation support. Geotechnical Special Publication, 2017, pp. 124-134.

58. Canoglu M.C. Selection of suitable dam axis location considering permeability and grout curtain optimization. Environmental and Engineering Geoscience, 2019, vol. 25, no. 1, pp. 15-25.

59. Wang F., Shi M., Liu W., Zhong Y., Wang X. Polymer grouting method for constructing ultra-thin anti-seepage wall. Patent USA no. 20140314498, 2014.

60. Deng M.J. Advances in key technology for concrete face dams with deep overburden layers under cold and seismic conditions. Chinese Journal of Geotechnical Engineering, 2012, vol. 34, no. 6, pp. 985-996.

61. Hu J.H., Wang R., Hu M.J., Zhou K.P. Test and mechanism of horizontal plastic drain in permafrost regions embankment. Zhongnan Daxue Xuebao (Ziran Kexue Ban)/Journal of Central South University (Science and Technology), 2009, vol. 40, no. 5, pp. $1451-1456$

62. Xuefu Z., Yaonan Z. Study on a new-styled measure for treating water leakage of the permafrost tunnels. Tunnelling and Underground Space Technology, 2006, vol. 21, no. 6, pp. 656-667.

63. Shen Z., Qiu L., Zhou H. Review of seepage control of earthrockfill dams on thick overburden layer. Advances in Science and Technology of Water Resources, 2015, vol. 35, no. 5, pp. 27-35.

64. Hinchberger S., Weck J., Newson T. Mechanical and hydraulic characterization of plastic concrete for seepage cut-off walls. $\mathrm{Ca}$ nadian Geotechnical Journal, 2010, vol. 47, no. 4, pp. 461-471.

65. Gancarz P.M., Minturn J.E., Grobler N.J., Van Dyk D. Polymer emulsion grouting for water cutoff in tunnel structures. Geotechnical Special Publication, 2017, pp. 295-302.

66. Guo C., Chu X., Wang F. The feasibility of non-water reaction polymer grouting technology application in seepage prevention for tailings reservoirs. Water Science and Technology: Water Supply, 2018, vol. 18, no. 1, pp. 203-213.

Received 13 March 2020.

\section{Information about the authors}

Nikolay V. Yurkevich, Cand. Sc., head of the laboratory, Trofimuk Institute of Petroleum Geology and Geophysics. Natalia V. Yurkevich, Cand. Sc., head of the laboratory, Trofimuk Institute of Petroleum Geology and Geophysics. Vadim N. Gureyev, Cand. Sc., senior researcher, Trofimuk Institute of Petroleum Geology and Geophysics; Novosibirsk State Technical University.

Nikolay A. Mazov, Cand. Sc., head of the information-analytic center, Trofimuk Institute of Petroleum Geology and Geophysics. 